\title{
Determining resectability inpancreatic tumors: Review of 70 cases
}

\author{
Ashraf Sobhy Zakaria*1, Mohammed Gamil ${ }^{1}$, Hussein Okasha², Ali Hassan Mebed ${ }^{1}$, Reda Hassan Tabashy ${ }^{3}$ \\ ${ }^{1}$ Surgical oncology department, National Cancer Institute Cairo University, Cairo, Egypt \\ ${ }^{2}$ Gastroenterology \& Hepatology Faculty of Medicine Cairo University, Cairo, Egypt \\ ${ }^{3}$ Radiodiagnosis National Cancer Institute Cairo University NCl Cairo University, Cairo, Egypt
}

Received: January 9, 2019

DOI: $10.5430 /$ jst.v9n1p9
Accepted: January 10, 2019

Online Published: January 16, 2019

\begin{abstract}
Background: Endoscopic ultrasound (EUS) has gradually become the main stream method of the diagnosis and local treatment of pancreatic tumors. Endoscopic ultrasound is frequently used in making the cytological diagnosis of pancreatic cancer and its great role in the pre-operative staging of pancreatic tumors.

Objective: To evaluate the role of EUS in diagnosis and treatment of pancreatic tumors prospectively for 2 years study 2014-2015. Patients and methods: Prospective study including 70 patients who presented with pancreatic tumors underwent EUS at the endoscopy unit at Faculty of Medicine Cairo University and National Cancer Institute, Cairo University.

Results: Out of 70 patients; median age was 55 years (range 32-73 years). Males were $32(46 \%)$ and females were 38 (54\%). Jaundice was the main symptom 47 (67\%), clay colored stool $46(65.7 \%)$, dark urine $47(67 \%)$ and abdominal pain $50(71 \%)$. There were 20 patients with benign disease and 50 patient with malignant disease. The following results showing the accuracy of the EUS in detecting malignant pancreatic tumors; Sensitivity: $96.0 \%$, specificity: $75 \%$, PPV: $90.6 \%$, NPV: $88.2 \%$, accuracy: $90.0 \%$.

Conclusion: EUS can clarify locoregional spread when CT/MR are equivocal. EUS Elastography is a new application in the field of the endosonography and seems to be able to differentiate fibrous and benign tissue from malignant lesions. The combination of superior detection, good staging, tissue diagnosis and potential therapy makes EUS guided FNA a cost-effective modality.
\end{abstract}

Key Words: Local treatment, Endoscopic, Ultrasound, Pancreatic tumors

\footnotetext{
${ }^{*}$ Correspondence: Ashraf Sobhy Zakaria; Email: ashrafsobhy27@yahoo.com; Address: Surgical oncology department National Cancer Institute Cairo University, Egypt.
} 